\title{
The Impact of Phytophthora Root Rot on Water Extraction from Soil by Roots of Field-grown Processing Tomatoes
}

\author{
J.B. Ristaino' and J.M. Duniway ${ }^{2}$ \\ Department of Plant Pathology, University of California, Davis, CA 95616 \\ Additional index words. Lycopersicon esculentum, neutron probe, Phytophthora parasitic, water relations
}

\begin{abstract}
Processing tomatoes (Lycopersicon esculentum Mill.) grown in field plots with soil infested with or free of Phytophthora parasitic Dastur. were furrow-irrigated for 4 to 8 hours every 14 days (normal irrigation), for 4 to 8 hours every 28 days (less frequent irrigation), or for 4 to 8 and 24 hours on alternate irrigations every 14 days (prolonged irrigation). Disease developed more rapidly and symptom severity was greater in inoculated plants that received prolonged irrigation, whereas disease onset was delayed in inoculated plants that were irrigated less frequently. Water extraction by tomato roots from well-irrigated and noninfested soil was usually greatest at shallow depths and decreased with depth. When disease was increasing and soil moisture was high, diseased plants extracted less total water from all depths and significantly less water at shallow depths. Plants in the drier soil profiles extracted the greatest amounts of water at depths below $90 \mathrm{~cm}$, and diseased plants irrigated less frequently showed reductions in water extraction at shallow depths later in the season. Tomato root systems appeared to compensate for moderate levels of root disease at shallow depths by extracting more water from deeper in the profile.
\end{abstract}

Phytophthora parasitic commonly causes a root rot of processing tomatoes in California (Satour and Butler, 1967). Phytophthora root rot of tomato can become severe under saturated soil conditions associated with irrigation, as has been demonstrated for other phytophthora diseases (Duniway, 1983). Field experiments described previously (Ristaino et al., 1988) showed that variations in frequency and duration of furrow irrigation had large effects on the rate at which phytophthora root rot developed and caused yield loss in processing tomatoes. Prolonged irrigation accelerated disease development, while less frequent irrigations delayed disease onset and minimized yield loss. The time course of disease development also had major effects on plant phenology and above-ground dry matter accumulation (Ristaino et al., 1989).

Root rots caused by Phytophthora spp. induce severe water stress in infected host plants (Dawson and Weste, 1984; Duniway, 1977; Kittle and Gray, 1980; Sterne et al., 1978; Whiley et al., 1986). For example, severe root rot depressed leaf water potential, the accumulation of dry matter, and subsequent fruit yield in processing tomato (Ristaino et al., 1988, 1989). Phytophthora root rots may affect plant water status by either reducing root density in the soil or, more directly, by increasing resistance to water uptake within the plant (Dawson and Weste, 1984; Duniway, 1977; Kittle and Gray, 1980). However, root distribution in soil may also be affected by disease. Safflower plants grown in partitioned columns of soil compensated for disease in a compartment infested with $P$. cryptogea by growing additional roots in an adjacent noninfested compartment of soil where greater water uptake occurred (Liddell and Duniway, 1987).

Root growth is recognized as an important factor in the rate at which soilborne pathogens incite disease (Huisman, 1982). However, little is known about the effects of soilborne pathogens on root length density and distribution in soil (Kotcon et

Received for publication 2 July 1990. The cost of publishing this paper was defrayed in part by the payment of page charges. Under postal regulations, this paper therefore must be hereby marked advertisement solely to indicate this fact.

'Presently Assistant Professor, Dept. of Plant Pathology, North Carolina State Univ., Raleigh, NC 27695.

${ }^{2}$ Professor. al., 1984). While it is difficult to adequately measure root length and distribution in field soils, the neutron probe offers a quick, nondestructive method to determine water extraction patterns in soil (Greaten, 1981). The amount of water extracted from a given layer of soil depends largely on the root length density and soil water content in that layer (Brown and Scott, 1984; Reicosky et al., 1972; Taylor and Klepper, 1974). Therefore, soil water extraction patterns measured with a neutron probe can be used as indicators of rooting depth and distribution under field conditions (Taylor and Klepper, 1973).

Although root rots are known to induce water stress in their hosts, no studies have measured effects of disease on the rates at which plants extract water from soils in the field. The objective of this research was to study the influence of phytophthora root rot on water extraction by tomato roots at various soil depths in the field. Differential irrigation regimes were imposed that caused disease to increase at various rates; the effects of subsequent disease on water extraction were determined with a neutron probe. A preliminary report of this work has been published (Beagle-Ristaino and Duniway, 1987).

\section{Materials and Methods}

The measurements reported here were made in the Dept. of Plant Pathology's field, Univ. of California, Davis, in 1986 as part of an experiment described previously (Ristaino et al., 1988, 1989). 'Ferry Morse 6203' tomato was planted on single-row beds. One-half of the plots were infested with inoculum of $P$. parasitic when plants were 6 weeks old, as described by Ristaino et al. (1989). Furrows were irrigated uniformly for 4 h, 1 to 2 days after soil infestation. Subsequent irrigations, begun 2 weeks later, were applied differentially among treatments arranged in a split-plot design with inoculum vs. no inoculum as the main plots and three furrow irrigation regimes as subplots. In one treatment, irrigations were applied to the furrows for 4 to $8 \mathrm{~h}$ every 14 days (normal irrigation). In a second treatment, irrigations were done on the same days, but alternate irrigations were extended to maintain water in the furrows for $24 \mathrm{~h}$ to saturate the beds (prolonged irrigation). In the third treatment, alternate irrigations were withheld and water was applied to furrows for 4 to $8 \mathrm{~h}$ every 28 days (less frequent irrigation). Each treatment was replicated four times, and beds within ex- 
perimental units were $13.7 \mathrm{~m}$ long and contained an average of 65 plants. The incidence and severity of disease symptoms on tomato shoots were assessed visually every 2 weeks through the growing season, as described previously, and plants in noninoculated plots remained disease-free (Ristaino et al., 1988).

Volumetric soil water content was measured in each experimental unit using a neutron probe (Hydroprobe Model No. 503, Campbell Nuclear Pacific, Pacheco, Calif.). Aluminum access tubes were cut into $183-\mathrm{cm}$ lengths and installed vertically in the soil in the center of each bed by use of a hydraulic soil sampler. Neutron probe measurements were begun 62 days after planting (DAP) and taken weekly at $30-\mathrm{cm}$ increments to a depth of $150 \mathrm{~cm}$.

The neutron probe was calibrated in the field at the end of the season. Irrigations in the plots used for calibration were either applied at several times during the season or were withheld to allow soil around three access tubes to dry to a range of moisture contents. Count ratios used for calibration were determined at $30-\mathrm{cm}$ increments to $150 \mathrm{~cm}$ and included the entire range of count ratios measured during the growing season. Undisturbed soil cores and bulk samples were excavated from around the access tubes, and bulk density and gravimetric water contents were used to calculate volumetric water content $\left(\mathrm{cm}^{3}\right.$ water/cm³ soil) (Graecen, 1981; Hillel, 1980). A highly significant and linear relationship $(\mathrm{y}=0.25 \mathrm{x}-0.053, r=0.99)$ was found between count ratios ( $\mathrm{x}$ ) and volumetric water content of soil (y).

Rates of water extraction from soil were calculated for four l-week periods during the growing season. To minimize effects of drainage and unsaturated water flow in soil, each measurement period was initiated at least 6 days after irrigation and terminated the day before the next irrigation (Fig. 1). Changes in soil water content during the periods of measurement were assumed to be due largely to water extraction from soil by roots, and the results are expressed as the change in volumetric water content of soil per week. Total extraction for a given period was estimated by assuming that each measured change in water content represented that for a $30-\mathrm{cm}$ increment in depth. The water extraction data were subjected to analysis of variance using SAS statistical packages, and treatment sums of squares were partitioned using orthogonal contrasts. Least significant differences were also calculated to separate subplot means across main plots.

Soil at the field site was mapped as a Yolo loam over fine sand or fine sandy loam. A more detailed sampling and standard textural analysis (Hillel, 1980) showed that soil texture in the field was heterogeneous. Soils in the top $30 \mathrm{~cm}$ were either loams or clay loams and had clay contents ranging from $22 \%$ to $30 \%$. Soils at $60-$ and $120-\mathrm{cm}$ depths had higher sand contents and were loams and sandy loams, while soils at 90-cm depths were loams and silt loams. Soil bulk densities ranged from 1.31 to $1.5 \mathrm{~g} \cdot \mathrm{cm}^{-3}$.

\section{Results}

The first differential irrigations, applied 63 DAP, wetted the soil profile to various depths. Measurements of soil water content 1 day before (62 DAP) and 6 days after (69 DAP) irrigation showed that the prolonged $(24 \mathrm{~h})$ irrigation increased soil water content to depths of at least $150 \mathrm{~cm}$ (Fig. 2A), while the normal 4- to 8-h irrigation increased soil water content to a depth of only $60 \mathrm{~cm}$ (Fig. 2B). The less frequently irrigated plots were not irrigated at 63 DAP, and soil water content was depleted between 62 and 69 DAP at all depths (Fig. 2C). The soil water

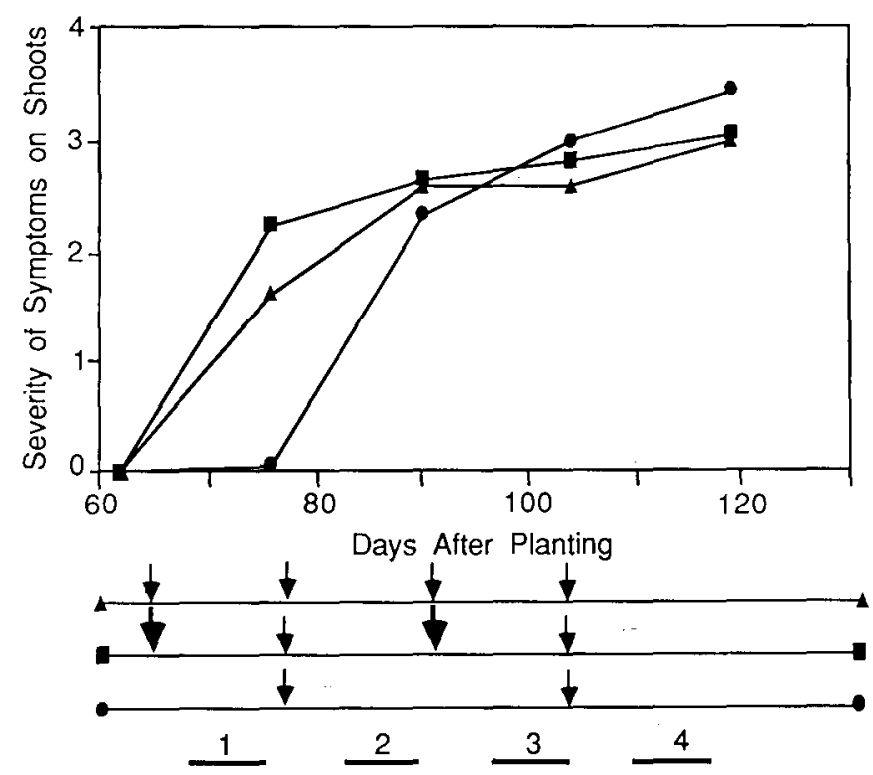

Fig. 1. Severity of phytophthora root rot plotted as a function of time after planting for processing tomatoes (redrawn from Fig. ID, Ristaino et al., 1988). Severity of symptoms on shoots was rated on a relative scale of $\mathrm{O}$ to 4 . Treatments were 4 - to 8 -h irrigations every 14 (triangles) or 28 days (circles), or alternating 4- to 8-h and 24-h irrigations every 14 days (squares). Heavy arrows beneath the graph indicate times of 24-h irrigation and light arrows indicate the times of 4- to 8-h irrigations. The four periods used for measuring water extraction from soil are shown below the time axis: period $1=69$ 76 DAP; period 2 = 83-90 DAP; period 3 = 97-104 DAP; and period $4=111-118$ DAP.

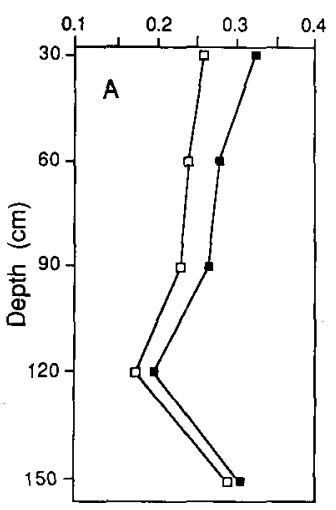

Soil Water Content $(V / V)$

Fig. 2. Water contents measured at five depths in the soil profile 62 (open symbols) and 69 (closed symbols) DAP of tomatoes. Data are shown for representative phytophthora-infested plots that were irrigated for 24 (A), or 4 to $8 \mathrm{~h}(\mathbf{B})$, or that were not irrigated (C) 63 DAP. Standard deviations of the means ranged from 0.009 to 0.05 , 0.006 to 0.04 , and 0.02 to 0.07 for $\mathbf{A}, \mathbf{B}$, and C, respectively.

contents measured 69 DAP illustrate the conditions under which first measurements of water extraction by roots were initiated.

Disease had large effects on water extraction by roots from soil. Disease symptoms developed rapidly on shoots between 62 and 76 DAP in inoculated plants irrigated 63 DAP, as reported by Ristaino et al. (1988), while noninoculated plants showed no above-ground symptoms of disease. During the first measurement period when disease symptoms were increasing in plots given the prolonged or normal irrigation (Fig. 1), total water extraction was significantly reduced (Fig. 3). Further- 


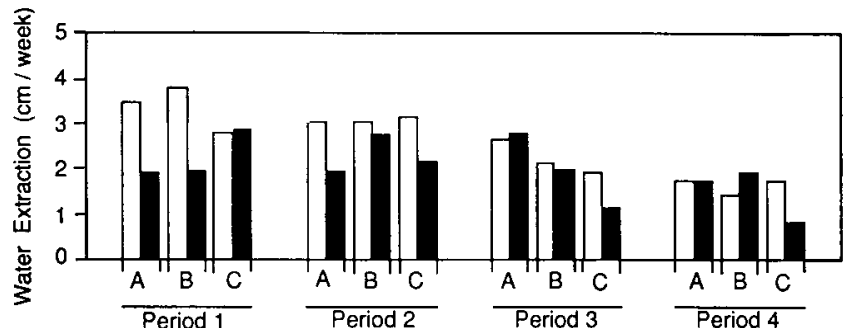

Fig. 3. Total water extraction from the soil profile measured during four l-week periods in plots of processing tomatoes either noninoculated (open bars) or inoculated (closed bars) with Phytophthora parasitic: A, prolonged 24-h irrigation; B, normal 4- to 8-h irrigation; and $\mathrm{C}$, less frequent irrigation. $\mathrm{LSD}_{0.05}=1.03,1.12,0.88$, and 1.17 for comparisons of means during periods $1,2,3$, and 4 , respectively.
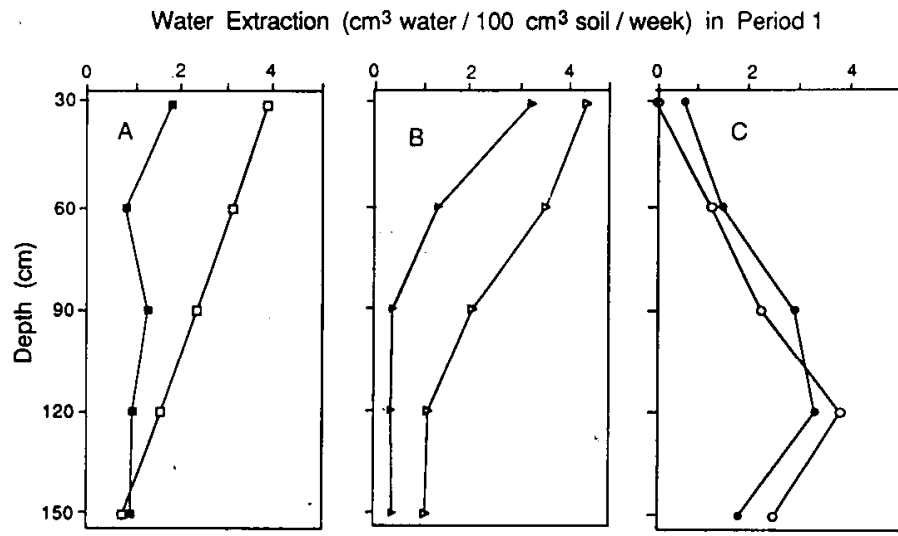

Fig. 4. Water extraction measured at various depths in soil between 69 and 76 DAP in plots of processing tomatoes either noninoculated (open symbols) or inoculated (closed symbols) with Phytophthxa parasitica (A) prolonged 24-h irrigation (squares), (B) normal 4- to 8-h irrigation (triangles), and (C) less frequent irrigation (circles). For comparison of means between inoculated and noninoculated plots, $\mathrm{LSD}_{0.05}=1.79,1.76,1.42,1.51$, and 1.38 at depths of 30 to 150 $\mathrm{cm}$, respectively.

more, during the first extraction period, 69-76 DAP (Fig. 1), extraction by noninoculated plants that were irrigated at 63 DAP was greatest at $30-\mathrm{cm}$ depths and decreased with depth (Fig. 4 A and B). Plants severely affected by $P$. parasitic following a prolonged irrigation extracted significantly less water at 30-, 60-, and 90-cm depths than noninoculated plants (Fig. 4A), even though inoculated and noninoculated plots had similar soil water contents at the beginning of the extraction period.

During this same period, inoculated plants given the normal irrigation showed a more gradual increase in disease severity than plants given prolonged irrigation (Fig. 1) and also extracted less water than noninoculated control plants at all depths examined, although water extraction was significantly reduced by disease only at 60 and $90 \mathrm{~cm}$ (Fig. 4B). In comparison to the other irrigation treatments, healthy plants irrigated less frequently extracted significantly less total water from all depths during period 1 (Fig. 3), but both inoculated and noninoculated plants extracted significantly more water from greater depths in the profile (Fig. 4C). Rates of water extraction were similar for inoculated and noninoculated plants irrigated less frequently during period 1 (Fig. 3), and inoculated plants did not exhibit aboveground symptoms of disease until after an irrigation was applied 77 DAP (Fig. 1). In all the irrigation treatments, water extraction during period 1 at $60-, 90-$, and $120-\mathrm{cm}$ depths was neg-

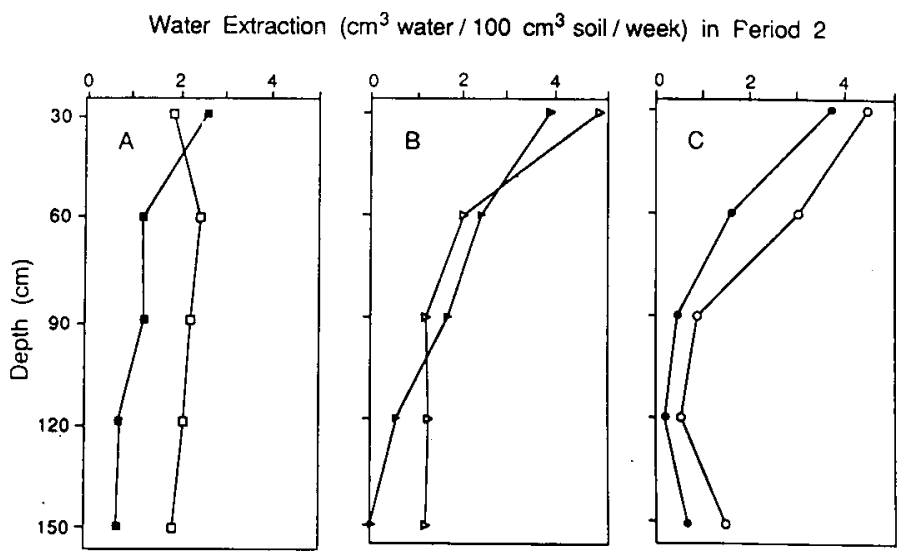

Fig. 5. Water extraction measured at various depths in soil between 83 and 90 DAP in plots of processing tomatoes either noninoculated (open symbols) or inoculated (closed symbols) with Phytophthora parasitica: (A) prolonged 24-h irrigation (squares), (B) normal 4- to. 8-h irrigation (triangles), and (C) less frequent irrigation (circles). For comparison of means between inoculated and noninoculated plots, $\mathrm{LSD}_{0.05}=1.28,1.76,2.21,1.46$, and 1.75 at depths of 30 to 150 $\mathrm{cm}$, respectively.

atively correlated with severity of above-ground symptoms of disease $(r=-0.45,-0.64$, and -0.48 for the three depths, respectively).

During the second extraction period, 83 to 90 DAP (Fig. 1), patterns of water extraction in the profile irrigated less frequently shifted in response to the irrigation applied 77 DAP, which increased the initial water content at $30 \mathrm{~cm}$ to $0.32(\mathrm{v} /$ v). Plants irrigated less frequently subsequently extracted the most water at the $30-\mathrm{cm}$ depth, and extraction decreased with depth (Fig. 5C). During this same period, when disease severity was near its maximum in inoculated plants given the prolonged or normal irrigations (Fig. 1), water extraction by inoculated plants from individual depth increments was not significantly reduced relative to noninoculated plants (Fig. 5 A and B). Disease reduced total extraction from the profile in all irrigation treatments (Fig. 3); however, the reduction was significant only with prolonged irrigation.

During the third extraction period, 97 to 104 DAP (Fig. 1), patterns of water extraction by noninoculated plants given prolonged or normal irrigations were similar to those observed during the first interval, i.e., extraction decreased with depth (Fig. $6 \mathrm{~A}$ and B). Inoculated plants extracted significantly less water than noninoculated plants at the $30-\mathrm{cm}$ depth in both the prolonged (Fig. 6A) and normal (Fig. 6B) irrigation treatments, but they extracted significantly more water at $120-$ and $150-\mathrm{cm}$ depths in the prolonged irrigation treatment (Fig. 6A). With normal irrigation, while extraction by inoculated plants also exceeded that by noninoculated plants at depths of 60 to $120 \mathrm{~cm}$, differences at depths of $60 \mathrm{~cm}$ or deeper were not significant (Fig. 6B). Furthermore, in treatments irrigated between periods 2 and 3, disease did not significantly decrease total extraction during period 3 (Fig. 3). Since less frequently irrigated plots were not irrigated for 20 days before the third extraction period (Fig. 1), the upper profile was relatively dry $(0.24 \mathrm{v} / \mathrm{v}$ water content), and extraction rates by both inoculated and noninoculated plants were low at the 30-cm depth (Fig. 6C). Extraction at depths $>60 \mathrm{~cm}$ by inoculated plants irrigated less frequently was decreased, but the difference at specific depths was significant at only $150 \mathrm{~cm}$ (Fig. 6C). Total water extraction by inoculated plants irrigated less frequently was less than that by 

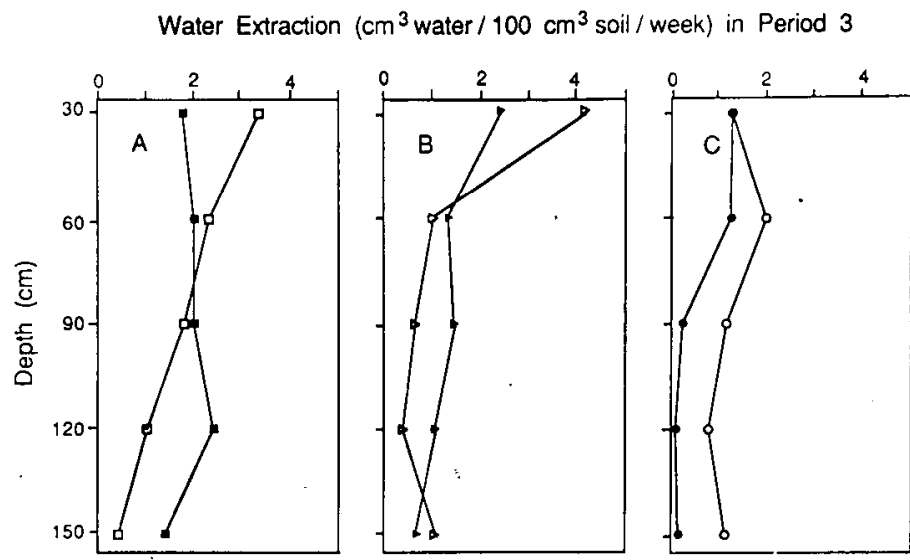

Fig. 6. Water extraction measured at various depths in soil between

97 and 104 DAP in plots of processing tomatoes either noninoculated (open symbols) or inoculated (closed symbols) with Phytophthora parasitica: (A) prolonged 24-h irrigation (squares), (B) normal 4-to 8-h irrigation (triangles), and (C) less frequent irrigation (circles). For comparison of means between inoculated and noninoculated plots, $\mathrm{LSD}_{0.05}=1.59,1.40,1.32,1.25$, and 0.82 at depths of 30 to 150 $\mathrm{cm}$, respectively.

Water Extraction $\left(\mathrm{cm}^{3}\right.$ water $/ 100 \mathrm{~cm}^{3}$ soil / week) in Period 4
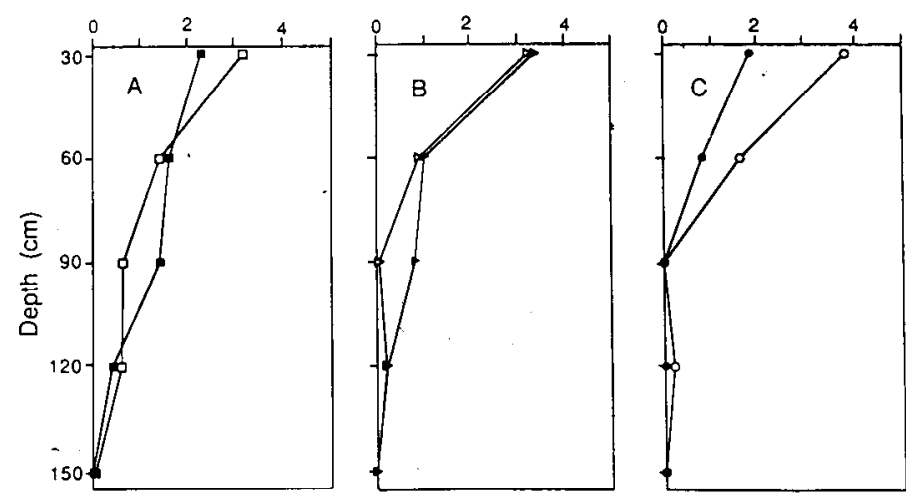

Fig. 7. Water extraction measured at various depths in soil between 111 and 118 DAP in plots of processing tomatoes either noninoculated (open symbols) or inoculated (closed symbols) with Phytophthora parasitica: (A) prolonged 24-h irrigation (squares), (B) normal 4- to 8-h irrigation (triangles), and (C) less frequent irrigation (circles). For comparison of means between inoculated and noninoculated plots, $\mathrm{LSD}_{0.05}=2.42,1.3,1.27,1.05$, and 3.14 at depths of 30 to $150 \mathrm{~cm}$, respectively.

noninoculated plants, although the difference was not significant (Fig. 3).

All irrigation treatments were applied 105 DAP, and during the fourth extraction period, 111-118 DAP (Fig. 1), extraction by all plants was greatest at the $30-$ and $60-\mathrm{cm}$ depths and there was little extraction below $90 \mathrm{~cm}$ (Fig. 7). Disease severity was still increasing in inoculated plants irrigated less frequently (Fig. 1 ), and root rot significantly reduced extraction at the $30-\mathrm{cm}$ depth (Fig. 7C). Total water extraction in this treatment was also reduced (Fig. 3), although the difference between inoculated and noninoculated plants was not significant. Despite the advanced stage of disease development, differences in extraction between inoculated and noninoculated plants were not significant at any depth in the other irrigation treatments (Figs. 3 and $7 \mathrm{~A}$ and $\mathrm{B}$ ).

\section{Discussion}

Healthy tomato plants in recently irrigated soil preferentially extracted-water from the upper $90 \mathrm{~cm}$ of the profile. This pattern of decreased water extraction with depth in relatively moist profiles, as well as the rates of total extraction reported here for healthy plants, are within the range of results reported previously for tomatoes grown under very similar field conditions (Kamgar Haghighi, 1980). Since water extraction from a wellirrigated profile is usually related directly to rooting density (Taylor and Klepper, 1973, 1978), it can be assumed that root densities were higher at shallow depths above $90 \mathrm{~cm}$ than at greater depths with normal and prolonged irrigation. Tomato roots can extend to a depth of $200 \mathrm{~cm}$ in soil, but the highest concentrations of roots are usually at depths above $45 \mathrm{~cm}$ (De Jong and Otinkorang, 1969; Hernandez-Suarez, 1988; Rudich and Luchinsky, 1986; Spencer, 1951; Widders and Lorenz, 1979). Others have demonstrated that tomato root growth is responsive to changes in soil water regime, with greatest root lengths located at shallow depths in wet treatments or concentrated in wet areas around drip emitters (Bar Yosef et al., 1980; Salter, 1954). Phytophthora root rot decreased total water extraction from the soil profile during periods when the severity of symptoms increased (Figs. 1 and 3). Root rot tended to reduce water extraction at shallow depths whenever moisture was available at those depths and disease symptoms were progressing. Since inoculum was placed at depths above $30 \mathrm{~cm}$ in the profile, the probability of root-pathogen contact was great in well-irrigated plots and disease increased. Soil matric potentials in these plots were conducive for zoospore release and infection after irrigation in this and previous studies (Ristaino et al., 1988). In addition, higher densities of roots in the top of the moist profiles may have increased the probability of root-pathogen contacts.

Inoculated plants in plots irrigated less frequently did not exhibit reduced water extraction when above-ground symptoms of disease were not apparent (Figs. 1 and 3). These plants extracted the most water at depths $>90 \mathrm{~cm}$ during period 1 (Fig. $4 C)$. Shifts in water extraction and rooting to greater depths in soil during drying cycles have been observed in cotton and tomato (Klepper et al., 1973; Salter, 1954). As soil water content is reduced under drying conditions, the mechanical impedence of soil increases and, subsequently, root growth is reduced (Hamblin, 1985). Evidently, a decrease in soil water content at shallow depths during a 21-day drying cycle in the less frequently irrigated plots encouraged greater growth and water extraction by tomato roots deep in the profile during period 1 .

Later in the season, after symptom severity stopped increasing, diseased plants given prolonged or normal irrigations began to compensate for reductions in water extraction at shallow depths by extracting more water at depths $>60$ or $90 \mathrm{~cm}$ (Fig. $6 \mathrm{~A}$ and B). An increase in water extraction by diseased plants at greater depths may have been due to increased root growth and/or increased water uptake per unit length of root. Tomato plants grown in soil compartments containing differentially salinized soil compensate for salinity stress in parts of the soil by producing more roots and extracting more water where salinity is low (Papadopoulous et al., 1985). At the time diseased plants extracted more water than healthy plants deep in the profile, advanced symptoms of disease were still apparent above ground. However, in our other studies, renewed vegetative growth was observed in plants in these plots late in the season (Ristaino et al., 1989), growth that could have been preceded by root growth and the subsequent increase in extraction deep in the profile. 
Disease effects on water extraction from soil by plants with less frequent irrigation differed from those described for plants irrigated every 14 days. After the onset of disease symptoms, and in those measurement periods initiated 1 week after irrigations (Fig. 1), disease reduced extraction from shallow depths where extraction by healthy plants was greatest (Figs. 5C and 7C); when measurements were initiated 3 weeks after irrigation, disease reduced extraction at greater depths (Fig. 6C). In addition, symptom severity continued to increase and total extraction by diseased plants was reduced during measurement periods 2-4, although these differences were not significant (Figs. 1 and 3). A comparison of the results obtained for less frequently and more frequently irrigated plants confirms that the negative impacts of disease on water extraction are manifested more during rather than after periods of symptom development.

No significant differences were found in extraction between inoculated and noninoculated plants given prolonged or normal irrigations late in the season. Resumed root growth may have increased water extraction by diseased plants at shallow depths, but senescence probably also decreased extraction by healthy plants (Hemandez-Suarez, 1988). Pan evaporation rates measured at a nearby weather station were 71, 80, 64, and $69 \mathrm{~mm}$ for measurement periods 1-4, respectively. A comparison of total extraction in periods 1 and 4 (Fig. 3), therefore, suggests that canopy and/or root senescence was effectively reducing transpiration and extraction by healthy plants in period 4. A previous study found the majority of the functional roots remained above $30 \mathrm{~cm}$ in the profile as tomato plants matured (De Jong and Otinkorang, 1969). The lack of change in water content at several of the greater depths late in the season (Fig. 7) also suggests that drainage did not cause significant soil water depletion during the measurement periods.

Several possible mechanisms may explain reduced water uptake by diseased roots. Phytophthora root rots cause significant increases in root resistance to water uptake, and as a consequence, they have been shown to cause reductions in leaf water potential in eucalyptus, safflower, avocado, and tomato (Dawson and Weste, 1984; Duniway, 1977; Ristaino et al., 1988; Sterne et al., 1978). Phytophthora species also cause reductions in size of root systems, but the loss of root length appears to be responsible for only a fraction of the total increase in root system resistance to water uptake caused by phytophthora root rots (Dawson and Weste, 1984). Fungus-mediated changes in plant hormones, xylem plugging, or fungal toxins may be involved in impairment of water uptake in diseased plants (Dawson and Weste, 1984; Duniway, 1977). The location of severe infections on roots may also be important in determining the overall effect of disease on water uptake by roots and plant water potential. Phytophthora-infected plants may be able to compensate for severe disease on a portion of the root system by extracting greater amounts of water through noninfected regions of the root system. However, if severe lesions are present on the major tap roots or the stem, water uptake will be reduced greatly and plant water status will suffer, regardless of other compensating effects on water uptake by roots (Duniway, 1977). In addition, disease effects on stomatal resistance and canopy structure may cause water extraction from soil to be reduced.

Irrigation frequency and duration had significant effects on the progress of phytophthora root rot and subsequent variations in disease had large impacts on water extraction by tomato roots in field soil. Clearly, the early phases of disease development reduced water extraction from the upper portion of the profile by plants irrigated on the 14-day schedule. Later in the season, disease also reduced water extraction by roots of plants given less frequent irrigations, i.e., every 28 days. To some extent, tomato root systems compensated for severe disease early in the season by extracting more water at greater depths in the profile. Further research to quantify pathogen impacts relative to root length densities and numbers and locations of infection sites on roots in the field would lead to a better understanding of the impacts of soilborne pathogens on root function.

\section{Literature Cited}

Bar Yosef, B., C. Stammers, and B. Sagiv. 1980. Growth of trickle irrigation tomatoes as related to rooting volume and uptake of $\mathrm{N}$ and water. Agron. J. 72:815-822.

Beagle-Ristaino, J.E. and J.M. Duniway. 1987. The impact of phytophthora root rot on water extraction from soil by field-grown processing tomatoes. Phytopathology 77:1744. (Abstr.)

Brown, D.A. and H.D. Scott. 1984. Dependence of crop growth and yield on root development and activity, p. 101-136. In: S.A. Barber and D.R. Bouldin (eds.). Roots, nutrient and water influx, and plant growth. ASA Special Publ. 49, Madison, Wis.

Dawson, P. and G. Weste. 1984. Impact of root infection by Phytophthora cinnamomi on the water relations of two Eucalyptus species that differ in susceptibility. Phytopathology 74:486-490.

De Jong, E. and E.S. Otinkorang. 1969. Measurement of root distribution of irrigated tomatoes with P-32 injection technique. Can. J. Plant Sci. 49:69-74.

Duniway, J.M. 1977. Changes in resistance to water transport in safflower during the development of phytophthora root rot. Phytopathology 67:331-337.

Duniway, J.M. 1983. Role of physical factors in the development of phytophthora diseases, p. 175-187. In: D.C. Erwin, S. BartnickiGarcia, and P.H. Tsao (eds.). Phytophthora, its biology, taxonomy, ecology, and pathology. Amer. Phytopathol. Soc., St. Paul, Minn.

Greaten, E.L. 1981. Soil water assessment by the neutron method. CSIRO Austral. Div. Soils, Adelaide, Australia.

Hamblin, A.P. 1985. The influence of soil structure on water movement, crop root growth, and water uptake. Adv. Agr. 38:95-158.

Hernandez-Suarez, M. 1988. Modeling irrigation scheduling and its components, and optimization of water delivery schedules with dynamic programming and stochastic $\mathrm{ET}_{\mathrm{o}}$ data. PhD Diss., Univ. of California, Davis.

Hillel, D. 1980. Introduction to soil physics. Academic, Orlando, Fla. Huisman, O.C. 1982. Interrelations of root growth dynamics to epidemiology of root invading fungi. Annu. Rev. Phytopathol. 20:203207.

Kamgar Haghighi, A.A. 1980. Effects of variable water supply on growth parameters, partitioning of assimilates and water-production functions of processing tomatoes. PhD Diss., Univ. of California, Davis.

Kittle, D.R. and L.E. Gray. 1980. Effects of infection by Phytophthora megasperma var. sojae on the water relations of soybean. Crop Sci. 20:504-507.

Klepper, B., H.M. Taylor, M.G. Huck, and E.L. Fiscus. 1973. Water relations and growth of cotton in drying soil. Agron. J. 65:307-310.

Kotcon, J. B., D.J. Rouse, and J.E. Mitchell, 1984. Dynamics of root growth in potato fields affected by early dying syndrome. Phytopathology 74:462-467.

Liddell, C.M. and J.M. Duniway. 1987. Changes in water uptake and root distribution occurring during the development of phytophthora root rot in safflower. Phytopathology 77:1745. (Abstr.)

Papadopoulos, I., V.V. Rendig, and F.E. Broadbent. 1985. Growth, nutrition, and water uptake of tomato plants with divided roots growing in differentially salinized soil. Agron. J. 77:21-26.

Reicosky, D. C., R.J. Millington, A. Klute, and D.B. Peters. 1972. Patterns of water uptake and root distribution of soybeans (Glycine max) in the presence of a water table. Agron. J. 64:292-297.

Ristaino, J. B., J.M. Duniway, and J.J. Marois. 1988. Influence of frequency and duration of furrow irrigation on the development of 
phytophthora root rot and yield in processing tomatoes. Phytopathology 78:1701-1706.

Ristaino, J. B., J.M. Duniway, and J.J. Marois. 1989. The influence of irrigation schedule and phytophthora root rot on growth, phenology, and yield of processing tomatoes. J. Amer. Soc. Hort. Sci. 114:556-561.

Rudich, J. and V. Luchinsky. 1986. Water economy, p. 335-367. In: J.G. Atherton and J. Rudich (eds.). The tomato crop: A scientific basis for improvement. Chapman and Hall, New York.

Salter, P.J. 1954. The effects of different water regimes on the growth of plants under glass. I. Experiments with tomatoes (Lycopersicon esculentum Mill.). J. Hort. Sci. 29:258-268.

Satour, M.M. and E.E. Butler. 1967. A root and crown rot of tomato caused by Phytophthora parasitica. Phytopathology 57:510-515.

Spencer, K. 1951. Tomato root distribution under furrow irrigation. Austral. J. Agr. Res. 2:118-125.
Sterne, R.E., M.R. Kaufman, and G.A. Zentmyer. 1978. Effect of phytophthora root rot on water relations of avocado: Interpretation with a water transport model. Phytopathology 68:595-602.

Taylor, H.M. and B. Klepper. 1973. Rooting density and water extraction patterns for corn (Zea mays L.). Agron. J. 65:965-968.

Taylor, H.M. and B. Klepper. 1974. Water relations of cotton. I. Root growth and water use as related to top growth and soil water content. Agron. J. 66:584-588.

Taylor, H.M. and B. Klepper. 1978. The role of rooting characteristics in the supply of water to plants. Adv. Agron. 30:99-128.

Whiley, A.W., K.G. Pegg, J.B. Saranah, and L.I. Forsberg. 1986. The control of phytophthora root rot of avocado with fungicides and the effect of the disease on water relations, yield, and ring neck. Austral. J. Expt. Agr. 26:249-253.

Widders, LE. and O.A. Lorenz. 1979. Tomato root development as related to potassium nutrition. J. Amer. Soc. Hort. Sci. 104:216-220. 